\title{
Daniel Murillo Licea, 2005, "Encima del mar está el cerro y ahí está el Anjel". Significación del agua y cosmovisión en una comunidad tsotsil, Instituto Mexicano de Tecnología del Agua, México
}

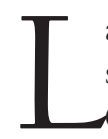
a región Los Altos de Chiapas es reconocida no sólo por la fama de la ciudad colonial de San Cristóbal de Las Casas o por su diversidad cultural local y las irrupciones históricas que han llevado el nombre de Chiapas a muchas partes del mundo. Esta región ha sido también campo de estudio para reconocidos intelectuales del extranjero, sobre todo a finales de la primera mitad y comienzos de la segunda del siglo pasado. Por mencionar a algunos: Frans y Gertrude Bloom, Gary H. Gossen, Evon Z. Vogt, Calixta Guiteras, Alfonso Villa-Rojas, June Nash, Mario Alberto Ruz, entre otros. Todos ellos considerados ya íconos de los estudios antropológicos e históricos de la región, ampliamente recomendados y consultados. En las últimas décadas, la orientación de los estudios se ha inclinado a explicar los procesos y cambios sociales como efectos del levantamiento armado de 1994 y pocos investigadores continúan explorando las múltiples facetas de las cosmovisiones indígenas ahora no sólo de los Altos, sino también de otras regiones del estado.

Sirva este breve panorama para contextualizar la pertinencia de un libro publicado en el 2005 por el Instituto Mexicano de Tecnología del Agua (IMTA) intitulado Encima del mar está el cerro y ahí está el Anjel". Significación del agua y cosmovisión de una comunidad tzotzil de Daniel Murillo Licea. La relevancia del libro no sólo tiene que ver con la amplitud de su contenido y el uso de la tradición oral como fuente de estudio, sino con la conclusión del propósito inicial que motivó la investigación sobre la significación del agua en las comunidades indígenas: la funcionalidad de la tecnología acorde a las características y necesidades culturales de la región. El autor advierte al respecto: “...los procesos sociales tienen que ver con los procesos tecnológicos y productivos, hay un enlace entre unos y otros y la bisagra que se desdobla para hacerlos funcionar parte de lo subjetivo, de eso que no puede verse pero que obliga a la actuación, a la comprensión, a la discusión, al entendimiento, a la comunicación. Y sin esa parte, invisible, la tecnología puede convertirse en un aparato sin uso alguno" (p. 10).

En la parte introductoria del libro, el autor comenta el tratamiento para la tradición oral pues debido a su naturaleza cambiante requiere, para su recopilación y análisis, de estrategias y metodologías adecuadas, como fue su caso: “...privilegié la aparición de textos orales como corpus de investigación. Este corpus se ha dividido en dos etapas sustanciales: una que tiene que ver con un eje individual-colectivo y que recoge las experiencias subjetivas de cada entrevistado; $y$ otro colectivo-individual, que recoge el saber comunitario y que se refleja a través del lenguaje y la expresión per- 
sonal". La combinación de técnicas de investigación propias de la etnografía y el análisis retrospectivo de la información, le da al trabajo la cualidad de etnohistoria. El libro contiene los capítulos siguientes:

1. Zona de estudio y la comunidad de Pozuelos.

2. Organización social y religiosa del agua.

3. La tradición oral en Pozuelos y la significación del agua.

4. La ritualidad en Pozuelos: Espacio y tiempo.

5. El agua y el mundo sobrenatural.

6. Conclusiones. Jun ko'on te oyun ta Pozuelos.

7. Apéndice: Relatos de Pozuelos.

8. Bibliografía, y

9. Fotos.

La comunidad Pozuelos pertenece al municipio de San Juan Chamula y se encuentra en las proximidades de San Cristóbal de Las Casas. Además de enumerar habitantes según datos del INEGI, también se detallan los rasgos culturales que caracterizan a esta comunidad y, en general, a las demás de la basta región: origen mítico, entorno geográfico, elementos simbólico-culturales como los dioses, el tiempo, el espacio y el alma y, por supuesto, las concepciones del agua, destacando así la importancia de los manantiales y las montañas aledañas. Asimismo, se describe y analiza el entramado de relaciones sociales y religiosas tanto intracomunitaria como intercomunitaria dirigidas por autoridades civiles y religiosas, patronatos de agua y mayordomías (martomavo'), respectivamente, para regular el cuidado, el festejo y el buen uso del agua en la comunidad.

En el capítulo tres el autor expone las principales características de la tradición oral, cuestiona el tratamiento y el abandono en que se encuentra como fuente de estudio para diferentes disciplinas sociales. Describe tres medios que reproducen la oralidad, a saber: la cotidianidad, donde la experiencia doméstica y agrícola son demarcadas por las actividades realizadas; la actividad ritual, que debe conjugar la oralidad, el comportamiento, lo visual, lo auditivo, lo olfativo y "Esta actividad ritual es en la que se privilegia la tradición oral" (p. 60).

Esta afirmación puede generar discrepancias, aún más cuando dice, en función de los espacios físicos como tercer medio: "no hay leyenda, no hay cuento, no hay rezo si no hay contacto con el cerro, el bosque, el manantial, la ceremonia, el espacio sagrado; si no hay comunicación con los dioses" (p. 61). Si bien la interacción de la sociedad con su medio, con su pasado y presente le permite reproducir pasajes míticos y conjugarlos con las situaciones cotidianas, no todas las narraciones se inscriben en la esfera de lo sagrado, como las migraciones, las epidemias, las guerras, por ejemplo.

Acerca de los rezos, dice: “...las palabras sagradas, dirigidas a los seres sobrenaturales, como el Anjel, tiene una parte de repetición, pero mucho de improvisación" (p. 62), afirmando con ello que los rezadores dicen lo que sienten; pero "es un acercamiento del tipo de lenguaje que hablan los dioses; que contienen un sinnúmero de metáforas y evocan símbolos no fácilmente explicables". Por ejemplo, realiza un análisis del siguiente fragmento de rezo:

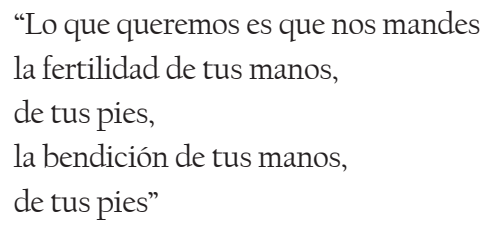

Su interpretación no me parece muy atinada pues sugiere que: "La mención a las manos y los pies puede interpretarse como que no falte ni el hacer de las manos: la creatividad, ni el hacer de los pies: el andar", y más adelante reafirma: “...también se puede interpretar que no falte la unión de la tierra y del cielo, donde se renueva la vida, donde la mano y el pie son la posibilidad de ser partícipe desde la forma y el andar" (pp. 70-71). En realidad, las manos y los pies hacen referencia a la 
personificación de la tierra y la naturaleza, concebido como un anciano protector y benefactor. De ahí que el agua se conciba como sangre de la tierra, es decir, sangre del dios que la personifica, llamado Mam o Pauahtun entre los antiguos mayas; y Dios N, entre los especialistas de esta cultura.

En el capítulo cuatro se describe minuciosamente los paisajes sagrados considerados como puertas de comunicación con el otro mundo; cómo el mito y el rito se encuentran siempre presentes en la cotidianidad, especialmente en los días festivos como el 3 de mayo, semana santa y el día de los muertos. Se realizan diferentes rituales en espacios específicos: la casa, dentro o fuera pero en la presencia de altares y cruces; las iglesias y puntos estratégicos en la geografía como las cuevas y las cruces en los caminos; por último, los sitios sagrados: manantiales, montañas y calvarios. En estos ritos el agua (abundancia) y la salud (orden, vida) constituyen la petición constante frente a una cruz que funciona como elemento cristiano, árbol sagrado y emblema del mundo mesoamericano. Bajo esta perspectiva, el autor muestra y enfatiza la continuidad de elementos míticos que provienen de la época prehispánica, hasta el grado de interrogarse: "La investidura que se hacía de humanos como encarnaciones de dioses es ya muy conocida en el pensamiento mesoamerican ¿Por qué no pensar que la representación que aparece en el Códice Dresde es la de un Martoma vo' de la antigüedad?" Es un entusiasmo sugerente que nos invita y compromete a incursionar de manera profunda en las prácticas culturales y religiosas de los actuales pueblos indígenas.
Por último, la relación entre el agua y el mundo sobrenatural puede resumirse en la imagen construida en el título del libro: "Encima del mar está el cerro y ahí está el Anjel”. En la cosmovisión actual las montañas son la réplica del inframundo, sitio que resguarda y provee de sustento a los seres humanos. La dualidad del inframundo en la concepción prehispánica como lugar de origen o resurgimiento (fertilidad) y como lugar oscuro y frío (muerte), en efecto prevalece en la actualidad. Para concluir el tema, el autor opina sobre la introducción de elementos ajenos a la cultura:

Lo que está fuera de la comunidad es proveedor de... caos: ...El contexto urbano, la modernidad, son elementos que vienen del caos. Una forma de mantener un cierto orden (y con ello todo lo que implica en cuanto a identidad y tradición, mantenimiento de mitos y ritos) es mantenerse a salvo a través de los dioses, (p. 148).

En este sentido, la introducción de la tecnología en una comunidad arraigada en sus tradiciones, la lógica de los cambios culturales la convierte en un bien colectivo para cumplir con sus funciones principales.

Finalmente, el libro es un excelente trabajo para conocer el pensamiento religioso actual de la comunidad de Pozuelos, de los pueblos indígenas de Chiapas y en general de los pueblos de origen mesoamericano.

$$
\begin{array}{r}
\text { Marceal Méndez Pérez } \\
\text { Centro de Lenguas, Arte y Literatura Indígenas } \\
\text { San Cristóbal de Las Casas, Chiapas; México. }
\end{array}
$$

